\title{
Pilot evaluation of summer flounder stock enhancement potential using experimental ecology
}

\author{
G. T. Kellison ${ }^{1,5, *}$, D. B. Eggleston ${ }^{1}$, J. C. Taylor ${ }^{2}$, J. S. Burke ${ }^{3}$, J. A. Osborne ${ }^{4}$ \\ ${ }^{1}$ Department of Marine, Earth, and Atmospheric Sciences, North Carolina State University, Raleigh, \\ North Carolina 27695-8208, USA \\ ${ }^{2}$ Department of Zoology, North Carolina State University, Raleigh, North Carolina 27695-7617, USA \\ ${ }^{3}$ National Ocean Service/National Marine Fisheries Service, Beaufort Laboratory, 101 Pivers Island Road, Beaufort, \\ North Carolina 28516, USA \\ ${ }^{4}$ Department of Statistics, North Carolina State University, Raleigh, North Carolina 27695-8203, USA \\ ${ }^{5}$ Present address: National Park Service/Biscayne National Park, 9700 SW 328th Street, Homestead, Florida 33033-5634, USA
}

\begin{abstract}
Stock enhancement is receiving increasing attention as a management tool to rebuild depleted fisheries. Unfortunately, proactive studies addressing the potential of stock enhancement to accomplish management goals prior to the implementation of enhancement efforts are uncommon. We outline an ecologically based, pilot protocol with which to address the potential of fisheries stock enhancement using hatchery-reared (HR) organisms, through trial releases coupled with laboratory and field experiments with juvenile summer flounder Paralichthys dentatus. Released HR fish did not persist in nursery habitats in which wild fish enjoyed relatively long residence times and high survival. Multiple lines of observations and evidence suggest that the relatively rapid disappearance of released HR fish was not a result of emigration. Caging and tethering trials, coupled with previously obtained behavioral data, suggest that the poor performance of HR fish in this study was a result of increased susceptibility to predation-induced mortality, as compared with wild fish. These results suggest that post-release survival of HR summer flounder might be increased by (1) improving methods of predator-conditioning, (2) releasing HR fish in sites that serve as natural refuges from predators, or (3) releasing fish at larger sizes. While poor post-release survival of HR summer flounder may limit the success of stock enhancement efforts with this species, we suggest that conclusions regarding the potential of stock enhancement as a management tool can only be made if biological information is coupled with economic information to predict economic costs associated with stock enhancement relative to costs associated with alternative management approaches.
\end{abstract}

KEY WORDS: Stock enhancement - Summer flounder · Hatchery - Wild · Growth · Predation · Survival

\section{INTRODUCTION}

In marine systems, there is a global pattern of depleted fishery stocks due to overexploitation, as well as habitat degradation and loss (Rosenberg et al. 1993, FAO 2002). One approach to rebuilding depleted fisheries is through stock enhancement, a practice in which large numbers of individuals of a target species are raised in controlled hatchery conditions and sub- sequently released into the wild. Stock enhancement is receiving increasing interest as a management tool (Munro \& Bell 1997, Bartley 1999), perhaps because its implementation appeals to our reluctance to impose harsher and less popular management or conservation methods (Travis et al. 1998). In the United States, states continuing or initiating stock enhancement programs or studies in recent years include Alaska, California, Florida, Hawaii, Maine, Maryland, Massachusetts, 
Oregon, South Carolina, Texas and Washington. Worldwide, stock enhancement has been or continues to be used in more than 25 countries spanning North and South America, Europe, Asia and Australia (Howell et al. 1999).

Multiple stock enhancement programs have been or continue to be considered successes (e.g. Kitada et al. 1992, McEachron et al. 1994, Hilborn 1998, Yamashita \& Yamada 1999), and experimental research has suggested that stock enhancement may be a viable fisheries-rebuilding method for some populations (e.g. Leber \& Arce 1996, Agnalt et al. 1999, Lenanton et al. 1999). In other systems, empirical research and economic analyses indicate that stock enhancement efforts are not or may not be logistically or economically recommendable (Hilborn 1998, Otterå 1999), and may have negative ecological impacts, e.g. possible genetic effects of HR fish on wild populations, spread of diseases from the hatchery to the wild, impact of released fishes on wild resident predator, prey, and competitor populations (with subsequent cascading effects), and possible displacement of wild conspecifics by aggressive hatchery-reared (HR) individuals (McMichael et al. 1999).

Because of the extensive effort necessary to estimate probable ecological ramifications of stock enhancement, it is advisable for managers to first address the likelihood of actually enhancing wild stocks because failure here would render the investigation of ecological effects unnecessary. Unfortunately, stock enhancement efforts often proceed with no indication of the likelihood of success (Borthern et al. 1999, Cowx 1999). If release scenarios can be developed so that post-release survival of HR organisms is deemed sufficient to accomplish biological and economic goals of enhancement efforts (as determined, for example, through population models), then managers may turn their attention to determining possible ecological effects of stock enhancement before enhancement efforts proceed. Conversely, if survival of HR organisms in the wild is insufficient to accomplish biological and economic goals of enhancement efforts, then it will be critical to determine the mechanism(s) underlying mortality if managers hope to develop methods to improve survival and subsequent likelihood of success of stock enhancement programs. Otherwise, poor survival rates may be seen as a 'red light' to stock enhancement efforts.

Finally, because habitat is extremely important in determining growth and survival of many estuarinedependent fishes (Pihl \& van der Veer 1992, Hoss \& Thayer 1993), the release of HR fishes in sub-optimal habitat may result in excessive mortality (Leber \& Arce 1996). Thus, for organisms that utilize a broad range of habitats, biological and economic potential of stock enhancement efforts may be dependent on the identification of optimal habitat(s) for release. The identification of optimal release habitat can be facilitated by conducting carefully designed field experiments and studies addressing habitat-specific growth and survival (e.g. Stoner 1994, Leber et al. 1998).

In North Carolina, USA, the summer flounder Paralichthys dentatus continues to be a subject of stock enhancement interest (Waters 1996, Rickards 1998, Waters \& Mosher 1999, Burke et al. 2000), due to a combination of heavy commercial and recreational exploitation, established techniques for mass hatchery-rearing (Burke et al. 1999), and considerable knowledge of summer flounder life-history (Powell \& Schwartz 1977, Burke et al. 1991, Burke 1995). We performed field experiments and trial releases in beach and marsh habitats to make inferences about the biological feasibility of stock enhancement for summer flounder, and to identify mechanisms underlying differences in survival between HR and wild individuals. The economic feasibility is evaluated elsewhere (G. T. Kellison \& D. B. Eggleston unpubl.).

\section{MATERIALS AND METHODS}

This study was conducted from April to July 1999 at the National Ocean Service/National Marine Fisheries Service laboratory in Beaufort, North Carolina, USA. Hatchery-reared fish were spawned from wild-caught broodstock and raised to early juvenile stage ( $\sim 30$ to $90 \mathrm{~mm}$ total length, TL) in the laboratory. Rearing conditions were as documented by Burke et al. (1999). Wild young-of-the-year juveniles ( $\sim 30$ to $90 \mathrm{~mm}$ TL) were collected from nearby shallow-water tidal flats in Beaufort, North Carolina, USA, with a $2 \mathrm{~m}$ beam trawl $(0.32 \mathrm{~cm}$ cod-end mesh size). All fieldwork was performed in the Newport River estuary, near Beaufort, North Carolina, USA ( $34^{\circ} 43^{\prime} 07^{\prime \prime} \mathrm{N}, 76^{\circ} 41^{\prime} 10^{\prime \prime} \mathrm{W}$; Fig. 1).

Physical characteristics of experimental sites. We selected 3 beach (Duke, Towne, and Radio) and 3 marsh (Prytherch, Haystacks, and Causeway) sites (Fig. 1) in which to perform mark-release, mark-recapture, caging, and tethering experiments. The experimental sites were chosen from a larger group of sites within each habitat because they were consistently (during the nursery season over a period of several years) occupied by juvenile wild flounder (G. T. Kellison \& J. C. Taylor unpubl. data). In general, there is considerable annual spatiotemporal variation in summer flounder abundance in Newport River Estuary nursery sites (G. T. Kellison \& D. B. Eggleston unpubl., G. T. Kellison \& J. C. Taylor unpubl. data). 
We measured 2 abiotic parameters (sediment percent silt-clay, replicated spatially, and average current speed, replicated temporally) in each site to justify our classification of sites as either high energy (beach) or low energy (marsh) habitats. We expected that beach sites would be characterized by lower sediment percent silt-clay, and higher average current speeds, than marsh habitats. Sediment cores $(3 \mathrm{~cm}$ diameter $\times 2 \mathrm{~cm}$ depth) were taken from 3 haphazardly chosen areas within the intertidal zone at each site immediately above the rising water line at mid-flood tide. Percent silt-clay values from each of these cores were then determined as described in Murphey \& Fonseca (1995). A mean value of percent silt-clay was then calculated for each site for comparisons between sites and habitats. Current speed was measured with a MarshMcBirney bi-directional electromagnetic current meter (model 523), with a velocity probe-head of $2.54 \mathrm{~cm}$ in diameter. Six current measurements $\left(1 \mathrm{~d}^{-1}\right.$; all sites measured on the same day) were made at each site during mid-flood or mid-ebb tide during early July. Care was taken to minimize the elapsed time between measurements at each of the sites to minimize possible differences in current speed attributable to changing tidal period. A mean current speed was then calculated for each site for comparisons between sites and habitats.

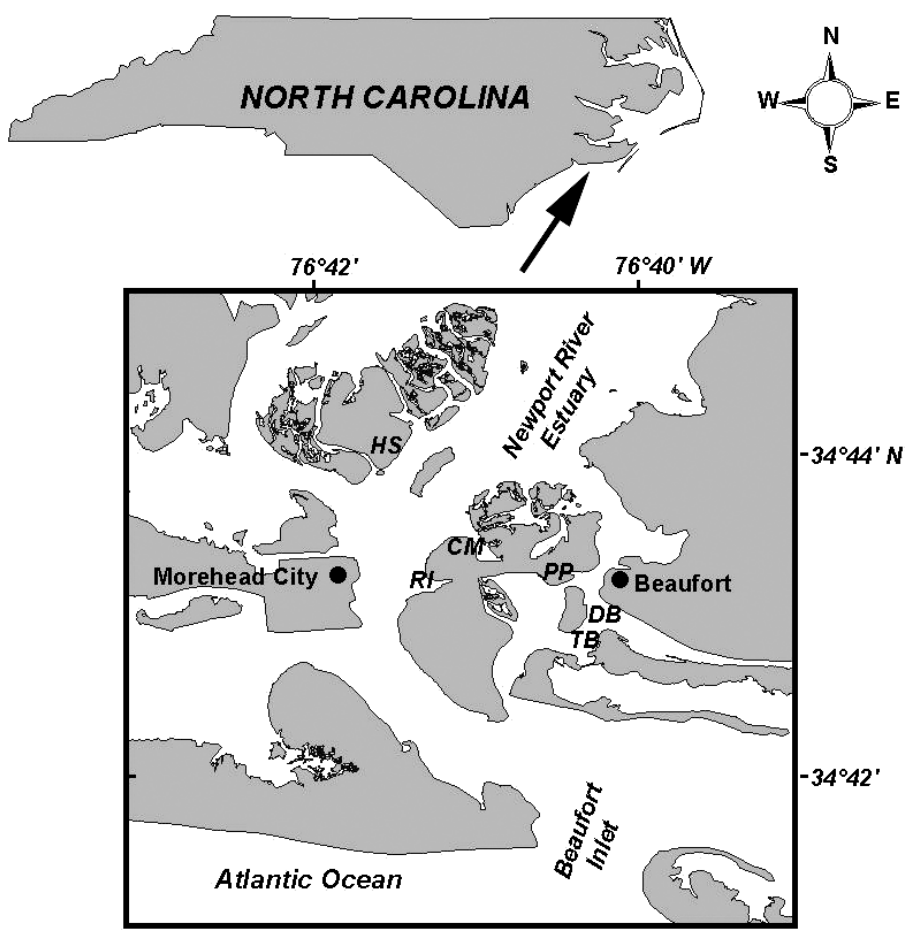

Fig. 1. Map of study sites, as indicated by HS (Haystacks Marsh), RI (Radio Island Beach), CM (Causeway Marsh), PP (Prytherch's Pond Marsh), DB (Duke Beach), and TB (Towne Beach)
We measured temperature, salinity, and dissolved oxygen with a hand-held YSI85 unit during each field sampling occasion (see below). Additionally, we rotated on-site temperature recorders with data loggers between sites to compare daily temperature variability between beach and marsh habitats.

Habitat-specific fish growth and days at liberty (DL) through mark-recapture trials. We performed markrecapture trials of wild juvenile summer flounder in 3 beach (Duke, Towne, and Radio) and 2 marsh (Prytherch and Haystacks) habitats to measure (1) habitatspecific fish growth rates and (2) DL, which is the number of days between the dates of first and final capture. We use DL measurements to make inferences about residence times, which we define as the length of time summer flounder utilized the beach and marsh habitats examined in this study. Wild fish (26 to $100 \mathrm{~mm}$ TL) were collected during temporally replicated sampling efforts (see below) with a hand-pulled $2 \mathrm{~m}$ beam trawl (0.32 cm cod-end mesh size) during mid-flood tide (three $\sim 30$ to $40 \mathrm{~m}$ trawls per site were performed on each sampling date). Captured fish were marked with 2 small acrylic paint injections on the blind side of the body with a 0.3 cc 29 -gauge hypodermic needle. This method, which used 4 paint colors and 6 positions on the fish, enabled us to individually mark up to 240 fish within a site. After marking, individual fish were placed in a recovery container for 5 to $15 \mathrm{~min}$ prior to their release. The goal of the recovery period was to reduce tag-related stress levels in the marked fish, which may have increased post-release susceptibility to predation in the wild. After each sampling event, marked fish were released in a haphazard spatial pattern so that just-marked fish were not aggregated after release (the total number of wild fish marked per site is presented in Table 1). Sites were sampled with the previously described $2 \mathrm{~m}$ beam trawl every 3 to $4 \mathrm{~d}$ from 15 April to 1 June, and every 2 to $3 \mathrm{~d}$ from 3 June

Table 1. Paralichthys dentatus. Site-specific area, number of hatchery-reared (HR) fish mass-released (June 2 or 3), and number of wild fish marked and released during the study. The number of HR fish released at each site was chosen so that post-release densities were constant across sites $(0.048$ fish $\mathrm{m}^{-2}$ ). NM = not measured

\begin{tabular}{|llrrc|}
\hline Habitat & Site & $\begin{array}{c}\text { Area } \\
\left(\mathrm{m}^{2}\right)\end{array}$ & $\begin{array}{c}\text { \# HR } \\
\text { released }\end{array}$ & $\begin{array}{c}\text { \# wild mark- } \\
\text { released }\end{array}$ \\
\hline Beach & Duke & 2565 & 122 & 233 \\
& Radio & 4512 & 214 & 131 \\
& Towne & $\mathrm{NM}$ & 0 & 91 \\
Marsh & Prytherch & 12324 & 589 & 54 \\
& Haystacks & 13022 & 621 & 128 \\
Total & & & 1546 & 637 \\
& & & & \\
\hline
\end{tabular}


(when HR fish were released in 4 of the 5 sites; see 'Trial releases' section) to 22 July. Mark-release occurred at each sampling event. When a marked fish was recaptured, the standard and total lengths (mm) were measured and recorded. Occasionally, fish with full guts were preserved in formalin for gut content analysis (see below).

Growth rates and days at liberty were calculated for each recaptured fish. Growth rates were calculated with the formula $G=\left(T L_{\mathrm{R}}-T L_{\mathrm{I}}\right) / n$, where $T L_{\mathrm{R}}$ is the total length at recapture, $T L_{\mathrm{I}}$ is the initial total length when first captured and marked, and $n$ is the number of days between original marking and recapture. We used total-length measurements to determine individual growth rates because the dark pigmentation of the caudal area of summer flounder juveniles at times made the determination of standard lengths difficult, and because logistical constraints prevented us from obtaining wet weights in the field. For fish with multiple recaptures, we did not calculate multiple growth rates based on each period at large, as these growth rates would not have been independent estimates of growth. Instead, we used the total length at final recapture as the $T L_{R}$ for these fish. This methodology allowed us to compare mean growth rates between habitats and sites with parametric tests, which operate under the assumption that observations are independent. Habitat effects on growth and days at liberty were investigated using linear mixed models with date of initial tagging (tag day) and total length at tagging (initial size) as covariates. The site factor, nested within habitats, was modeled as a random effect, and habitat as fixed. Covariates were included in the model if they satisfied the assumption of homogeneity of slopes, and had coefficients that were significantly different from zero ( $\mathrm{p}<0.05)$. This approach led to inclusion of 'tag day' in the model for growth rate and 'initial size' in the model for days at liberty. Appropriate degrees of freedom for $F$-ratios were determined according to Satterthwaite approximations (Satterthwaite 1946) using the MIXED procedure in SAS. Data for analyses of growth rates were $\log _{e}($ growth +1$)$-transformed to meet the assumption of homogeneity of variances. The percentage of wild fish recaptured ([number recaptured/number tagged] $\times 100$ ) was calculated for each site for later comparison with HR fish (see below).

Trial releases. In an attempt to measure habitatspecific growth and days at liberty of HR fish for comparison with wild fish, we performed trial releases of HR fish in 2 beach (Duke and Radio) and 2 marsh (Prytherch and Haystacks) sites in which we were already performing mark recapture trials for wild fish. Prior to release, HR fish were anti-predator conditioned by exposure to caged adult blue crabs Callinectes sapidus. This practice was based on previous labora- tory trials that suggest anti-predator conditioning may reduce predator-induced mortality rates of HR flounder (see Kellison et al. 2000 for a full description). Additionally, 4 to $5 \mathrm{~d}$ prior to release, we measured each HR fish to the nearest millimeter, and separated all fish into $5 \mathrm{~mm}$ size-classes. Fish were then marked with a size-class-specific tag so that, upon recapture, the release size of each fish could be determined to within $5 \mathrm{~mm}$. This process enabled us to look for potential differences in size-specific survival of HR fish (by comparing size-specific release and recapture data). Due to a lack of tank space, fish were then separated into 1 of 4 tanks based on total length: $<45,46$ to 60 , 61 to 75 , and $>75 \mathrm{~mm}$ (the range of released fish sizes was $\sim 30$ to $105 \mathrm{~mm}$ TL). For trial releases, equal proportions of each size class were released at each experimental site. Because the experimental sites differed in area, we manipulated numbers released at each site so that post-release densities $\left(0.048 \mathrm{fish}^{-2}\right)$ would be constant across sites (Table 1), thus controlling for possible density-dependent processes affecting growth or mortality. Post-release densities of HR fish were representative of natural densities of wild fish (mean $\sim 0.05 \mathrm{~m}^{-2}$ during June; G. T. Kellison pers. obs.). Fish were stocked at mid-flood tide on Duke Beach and Prytherch Marsh on 2 June, and on Radio Beach and Haystacks Marsh on 3 June. For stocking, fish were transported in multiple 981 coolers and released gradually (a few at a time; water depth $\sim 0.75$ to $1.25 \mathrm{~m}$ ) as the releasers slowly waded through each release site. A snorkeler observed the fish as they were released to make inferences about possible rapid emigration from the release sites, although observation of fish in Prytherch Marsh was limited due to the finegrained sediment suspended in the water from the footsteps of the releasers. To make inferences about possible emigration over longer time scales, we irregularly sampled outside of release sites during the remainder of the study.

All sites in which HR fish were released were sampled the following day (3 June for Duke and Prytherch, 4 June for Radio and Haystacks), and every 2 to $3 \mathrm{~d}$ until 22 July. Concurrently, we sampled the Towne Beach site every 2 to 3 d from 4 June to 22 July. Recaptured HR fish were measured as described above for wild fish. Because the HR fish were not tagged for individual identification prior to release, we were unable to determine growth rates from first-recaptured HR fish. Thus, HR fish recaptured for the first time after release were tagged for individual identification (by adding a second acrylic mark) at the time of recapture, and re-released. Individual growth rates were calculated for fish that were recaptured 2 or more times. In these cases, calculation of growth rates was as described for wild fish. DL for HR fish was calculated by 
determining the number of days between date of release and final capture and compared (pooled across sites) with those of wild fish using a non-parametric Wilcoxon 2-sample test. The percentage of HR fish recaptured ([number recaptured/number released] $\times$ 100) was calculated for each site, and compared (pooled across sites) to that of wild fish with a loglinear $G$-test.

Growth rates determined through caging. If the post-release survival of HR fish is poor in comparison to survival of wild fish in natural habitats, then an inability to consume food resources and grow in the wild may be the mechanism underlying the poor survival of HR fish. Caged fish were used to test the null hypothesis of no difference in habitat-specific growth rates between HR, high-density HR (HDHR), and wild fish. The HDHR treatment was included to test for a density effect on growth, since stock enhancement efforts are generally characterized by high postrelease densities. The cages were cylindrical in shape (diameter $=1.0 \mathrm{~m}$, height $=0.5 \mathrm{~m}$, total cage volume $=$ $0.4 \mathrm{~m}^{3}$ ) and consisted of a PVC-pipe frame enveloped in $1 \mathrm{~cm}$ nylon mesh, which allowed small fish and crustaceans to enter or exit the cages (G. T. Kellison pers. obs.; see also 'Stomach content analysis' section). Cages were weighted with $\sim 3.5 \mathrm{~kg}$ of net leads sewn into the circumference of the bottom portion of the cage frame. Cages were anchored with 2 bricks, through which steel rods were driven for additional cage stability. At each site, 9 cages (3 treatments; see below) were deployed at the edge of the subtidal zone adjacent to the spring low tide mark. Cages were placed approximately $1.5 \mathrm{~m}$ from neighboring cages so that the cages formed a row parallel to the shoreline (at Radio Beach, 2 rows of 5 and 4 cages, respectively, were deployed due to spatial limitations). This deployment strategy was designed so that fish in each cage would experience similar tidal conditions (depth and flow). Cages were stocked with site-specific sediment (1 to $2 \mathrm{~cm}$ depth) upon deployment. Cages were then left undisturbed for $7 \mathrm{~d}$ to allow epifaunal and infaunal recruitment to the sediment.

Twenty-four hours prior to stocking, HR (35 to $77 \mathrm{~mm}$ TL) and wild (34 to $68 \mathrm{~mm}$ TL) fish were haphazardly chosen from hatchery tanks and, for HR fish, randomly assigned to the low or high-density treatment. Fish were measured to the nearest millimeter (total length) and tagged for individual identification. Fish were then allowed to recover (but were not fed) until stocking the following day.

At each of 4 sites, cages were stocked with a single wild fish (3 replicates), a single HR fish (normal density treatment; 3 replicates), or $3 \mathrm{HR}$ fish (high-density treatment; 3 replicates), for a total of 9 cages. Caging trials were terminated after $3 \mathrm{wk}$, when fish were har- vested from cages and measured for standard and total lengths in the field. Fish were then euthanized with a lethal dose of MS222 and placed on ice to decelerate further digestion of food. Upon return to the laboratory, fish were preserved in formalin for subsequent stomach content analysis. Following termination of the first caging trial (18 May to 9 June), cages were restocked with sediment and again left undisturbed for $7 \mathrm{~d}$, at which time a second 3 wk caging trial (17 June to 8 July) was initiated with re-randomized treatment assignments. Thus, a total of 120 fish were caged for subsequent measurement of growth rates. Due to cage failure, 2 cases of human intervention and potential fish mortality, only 60 of the 120 caged fish were retrieved for analyses. Of these, 35 were used in statistical analyses (only one randomly chosen fish from each of the high-density cages was included to avoid pseudoreplication).

Growth rates for individual fish were calculated as $G=\left(T L_{\mathrm{F}}-T L_{\mathrm{I}}\right) / n$, where $T L_{\mathrm{F}}$ is the total length at the termination of the caging trial, $T L_{I}$ is the total length at initiation of the caging trial, and $n$ is the duration of the caging trial. Effects of fish status (fixed effect: normal density wild versus normal density HR versus HDHR) and habitats (fixed effect: beach versus marsh) on mean growth rates were analyzed using a mixed model (ANCOVA) with trial (first or second) as a fixed block effect and site as a random effect, nested in habitat. Because the missing cells associated with nonrecovered fish led to an incomplete, unbalanced design, the model including all higher-order terms was over-parameterized and unestimable. To prevent overparameterization, we excluded trial $\times$ treatment ('habitat' and 'fish status') interaction terms from the model (separate analyses run to examine potential trial $x$ treatment interactions indicated none were present; $p>0.80$ in both cases). The originally included covariate 'initial total length' was excluded from the model due to non-significance. Appropriate degrees of freedom for $F$-ratios were determined according to Satterthwaite approximations (Satterthwaite 1946) using the MIXED procedure in SAS. Data were $\log _{\mathrm{e}}($ growth +1$)$-transformed to meet the assumption of homogeneity of variances. For the HDHR treatment, growth from 1 of the 3 fish from each cage was randomly chosen for use in data analysis (Hurlbert 1984).

Stomach content analysis. Stomach contents of caged fish were analyzed to test the hypotheses that juvenile flounder diets would not differ in (1) consumption (mass of stomach contents) and (2) composition between HR, HDHR, and wild fish. Fish stomachs were removed, blotted dry with a paper towel, and weighed to the nearest $0.01 \mathrm{~g}$. Stomach contents were then removed and preserved in $95 \%$ alcohol for subsequent identification, and empty stomachs were reweighed. 
By subtracting the empty stomach weight from the full stomach weight, we calculated wet weight of stomach contents for each fish (Edgar \& Shaw 1995). Effects of fish status (wild versus HR versus HDHR) and habitats (beach versus marsh) on mean weight of stomach contents were analyzed using a mixed model (ANOVA) with trial (first or second) as a fixed block effect and site as a random effect, nested in habitat. As with the previous (cage growth) analysis, we excluded trial $\times$ treatment interaction terms from the model to prevent over-parameterization (separate analyses run to examine potential trial $\times$ treatment interactions indicated none were present; $p>0.37$ in both cases). The originally included covariate 'initial total length' was excluded from the model due to non-significance. Appropriate degrees of freedom for $F$-ratios were determined according to Satterthwaite approximations (Satterthwaite 1946) using the MIXED procedure in SAS. For the HDHR treatment, growth from 1 of the 3 fish from each cage was randomly chosen for use in data analysis (Hurlbert 1984). Data were $\log _{\mathrm{e}}$ transformed to meet the parametric assumption of homogeneity of variances. A total of 34 stomachs were used for statistical analysis (1 fish was lost prior to stomach removal).

To make inferences about treatment effects on diet composition, stomach contents were identified to the lowest possible taxa in terms of numerical percentage composition $(\% N)$, percent frequency of occurrence $(\% F)$, and volumetric percentage composition $(\% V)$. An index of relative importance (IRI) (Pinkas et al. 1971), defined as:

$$
\text { IRI }=(\% N+\% V) \times \% F
$$

was then calculated. IRI values were then standardized to $100 \%$ (\%IRI; Cortes 1997) for comparison of prey taxa (i) between treatments (fish status and habitat), where:

$$
\% \mathrm{IRI}_{i}=\frac{100 \times \mathrm{IRI}_{i}}{\sum_{i=1}^{n} \mathrm{IRI}}
$$

Prey taxa with a \%IRI value less than 5\% were combined into a single category labeled 'other' for simplicity of presentation. Since no statistical comparisons were made with these data, stomachs from all fish retrieved from cages (less 1 lost prior to stomach removal) were utilized to increase sample size $(n=59)$

Predation-induced mortality rates. If the postrelease survival of HR fish is poor in comparison to that of wild fish in natural habitats, then an increased susceptibility of HR fish to predation in the wild may be the mechanism underlying the poor survival of HR fish. Fish were tethered to test whether susceptibility to predation differed between HR and wild fish, and between beach and marsh habitats. Tethering was considered a valid method by which to compare relative measures of fish status- (wild versus HR) and habitat- (beach versus marsh) specific predation, since extensive laboratory observations and experiments made prior to this study (Kellison et al. in press) indicated no interaction between treatment and the use of tethers (Peterson \& Black 1994). Because of high rates of predation-induced mortality of tethered fish in preliminary trials lasting 6 to $24 \mathrm{~h}$ (100\% in all cases), trials used in statistical analyses were limited to $3 \mathrm{~h}$ intervals, which began $1.5 \mathrm{~h}$ prior to high tide and were terminated $1.5 \mathrm{~h}$ subsequent to high tide. For each trial, a $40 \mathrm{~m}$ weighted nylon line with 6 small loops (1 loop every $5 \mathrm{~m}$; no loops at either end) was deployed horizontally to the shoreline for a given tethering site. The line was positioned so that water depth over the line was $\sim 0.5 \mathrm{~m} 1.5 \mathrm{~h}$ prior to and subsequent to high tide. Three wild and 3 anti-predator conditioned HR fish were selected haphazardly from holding tanks and randomly assigned to 1 of the 6 loops in the nylon line. Fish were then tethered (through the dorsal musculature; Kellison 2000) on site. The free end of the tether was attached to 1 of the 6 loops in the nylon line with a small clamp. The length of the tether was $\sim 35 \mathrm{~cm}$, so that each tethered fish had an area of $\sim 0.4 \mathrm{~m}^{2}$ in which to move. Tethering trials were terminated after $3 \mathrm{~h}$, at which time each replicate fish was classified as either eaten or not eaten. Due to time constraints related to tidal pattern, we were only able to tether fish at 1 site per day. Trials were performed in late June in 3 beach (Duke, Radio, and Towne) and 3 marsh (Prytherch, Causeway, and Haystacks) sites. Trials were run at Towne Beach on 2 separate days. Trials, by site, occurred in random order. Results were analyzed with a log-linear $G$-test to test for the effects of fish status (HR versus wild) and habitat (beach versus marsh) on frequency of predator-induced mortality. A total of 42 fish were tethered.

\section{RESULTS}

\section{Physical characteristics of experimental sites}

Measurements of abiotic parameters (percent siltclay and current speed) indicated that our 'beach' sites were characterized by relatively higher energy than 'marsh' sites. Sediment percent silt-clay, which generally decreases as energy increases, was higher in all marsh sites (range $=24$ to $41 \%$ ) than in beach sites (range $=7$ to $11 \%$ ) (Table 2). Mean current speed was lower in all marsh sites (range 2 to $3 \mathrm{~cm} \mathrm{~s}^{-1}$ ) than beach sites (range 4 to $20 \mathrm{~cm} \mathrm{~s}^{-1}$ ) (Table 2). There was relatively large variability in current speeds between 
Table 2. Physical characteristics of beach and marsh sites. Temperature, dissolved oxygen, and salinity data are from point measurements taken during sampling. $\mathrm{NM}=$ not measured

\begin{tabular}{|llrrrrr|}
\hline Habitat & \multicolumn{1}{c}{ Site } & $\begin{array}{c}\text { \% Silt-clay } \\
( \pm \mathrm{SE})\end{array}$ & $\begin{array}{c}\text { Mean current } \\
\text { speed } \\
\left(\mathrm{cm} \mathrm{s}^{-1}\right)\end{array}$ & $\begin{array}{c}\text { Mean } \\
\text { temperature } \\
( \pm \mathrm{SE})\end{array}$ & $\begin{array}{c}\text { Mean dissolved } \\
\text { oxygen } \\
( \pm \mathrm{SE})\end{array}$ & $\begin{array}{c}\text { Mean } \\
\text { salinity } \\
( \pm \mathrm{SE})\end{array}$ \\
\hline Beach & Radio & $7.61 \pm 0.46$ & $5.82 \pm 0.69$ & $24.41 \pm 0.65$ & $6.74 \pm 0.14$ & $31.17 \pm 0.67$ \\
& Duke & $10.56 \pm 1.03$ & $3.99 \pm 0.73$ & $24.42 \pm 0.55$ & $6.68 \pm 0.14$ & $32.11 \pm 0.47$ \\
& Towne & $7.52 \pm 2.12$ & $19.62 \pm 4.90$ & $25.33 \pm 0.76$ & $6.73 \pm 0.17$ & $31.48 \pm 0.83$ \\
Marsh & Causeway & $41.17 \pm 1.73$ & $2.58 \pm 0.94$ & $\mathrm{NM}$ & $\mathrm{NM}$ & $\mathrm{NM}$ \\
& Prytherch & $24.03 \pm 2.63$ & $2.11 \pm 0.41$ & $25.80 \pm 0.88$ & $6.08 \pm 0.24$ & $31.78 \pm 0.54$ \\
& Haystacks & $26.70 \pm 2.33$ & $3.14 \pm 1.24$ & $25.72 \pm 0.64$ & $6.37 \pm 0.15$ & $31.25 \pm 0.67$ \\
\hline
\end{tabular}

beach sites, as mean current speed at Towne Beach was $\sim 3$ times greater than at Radio Beach, and nearly 5 times that at Duke Beach (Table 2). Mean temperature and dissolved oxygen regimes were generally similar across all sites, although daily variability in these parameters was typically greater in marsh sites (Kellison 2000).

\section{Habitat-specific fish growth and DL through mark-recapture trials}

Results from mark-recapture trials suggested that variability in mean growth rates of wild summer flounder between sites overshadowed possible differences in growth rates between habitats. There was no significant effect of habitat (beach versus marsh) on growth rate (nested ANCOVA; $F_{1,4.1}=4.53, \mathrm{p}=0.0981$ ) or days at liberty (nested ANCOVA $; F_{1,6.0}=2.12 ; \mathrm{p}=0.1958$ ) (Appendix 1). For growth, the back-transformed, least squares means and limits of the estimated 95\% confidence intervals (calculated by exponentiation of confidence limits about the means of the transformed data) were 0.64 (0.26 to 1.13) $\mathrm{mm} \mathrm{d}^{-1}$ for marsh $(\mathrm{n}=16)$ and 0.34 (0.11 to 0.61$) \mathrm{mm} \mathrm{d}^{-1}$ for beach $(\mathrm{n}=99)$ habitats. For DL, the means \pm SE were $27.66 \pm 5.88 \mathrm{~d}$ for marsh $(\mathrm{n}=16)$ and $17.55 \pm 3.66 \mathrm{~d}$ for beach $(\mathrm{n}=99)$ habitats. There was a significant effect of individual site on fish growth rates (nested ANCOVA; $F_{3,109}=5.41 ; \mathrm{p}=$ 0.0016; Fig. 2a) and days at liberty (ANCOVA; $F_{3,109}=$ 3.30; $\mathrm{p}=0.0232$; Fig. 2b) (Appendix 1).

\section{Trial releases}

Based on post-release observations of hundreds of released fish, most fish swam quickly to the benthos after release, where they buried themselves or remained motionless (unburied) on the benthos. No HR fish were observed in exposed tidal pools during ebb tide following release, suggesting that the HR fish
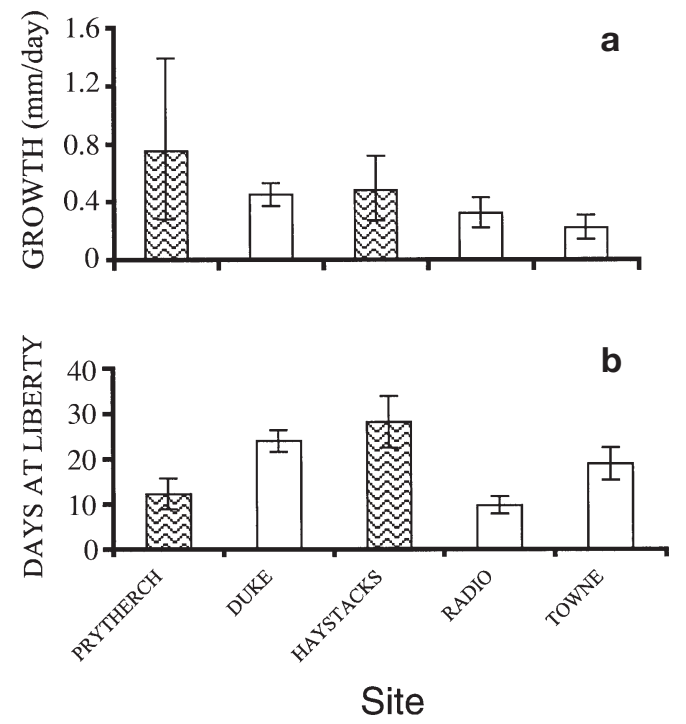

Fig. 2. Paralichthys dentatus. (a) Back-transformed mean growth rates ( \pm estimated $95 \%$ CI bounds) and (b) mean days at liberty $( \pm \mathrm{SE})$ of wild juvenile summer flounder in beach (white bar) and marsh (patterned bar) habitats based on markrecapture trials. Sample sizes (n) for (a) and (b): Prytherch $=6$, Duke $=61$, Haystacks $=10$, Radio $=15$, Towne $=23$. Since 'site (habitat)' was a random factor in the analyses, tests for significance for (a) and (b) were based on estimated variance components rather than on comparisons of site means

did not perish from stranding-induced mortality. No marked fish were recaptured outside of release sites.

Despite intensive post-release sampling ( every other day), only 30 of the 1546 HR fish initially released $(\sim 2 \%)$ were recaptured. For comparison, 18\% (115 of 637 ) of wild fish marked and released throughout the study and $16 \%$ (29 of 185) of the wild fish marked and released subsequent to June 3 (the latter release date of HR fish) were recaptured. A total of 73 percent (22 of 30 ) of the recaptured HR fish were caught within $1 \mathrm{wk}$ of release; the remaining 8 fish were recaptured during the following month of sampling. Size-frequencies of recaptured HR fish were nearly identical to sizefrequencies of released fish (Fig. 3). Four of the 30 


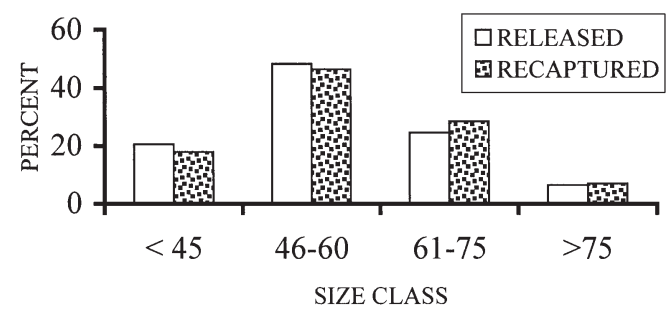

Fig. 3. Paralichthys dentatus. Percent of total number of released (white bars) and recaptured (mottled bars) hatcheryreared (HR) juvenile summer flounder belonging to various size-classes over a 50 d sampling period (total number released $=1546$; total number recaptured $=30$ )
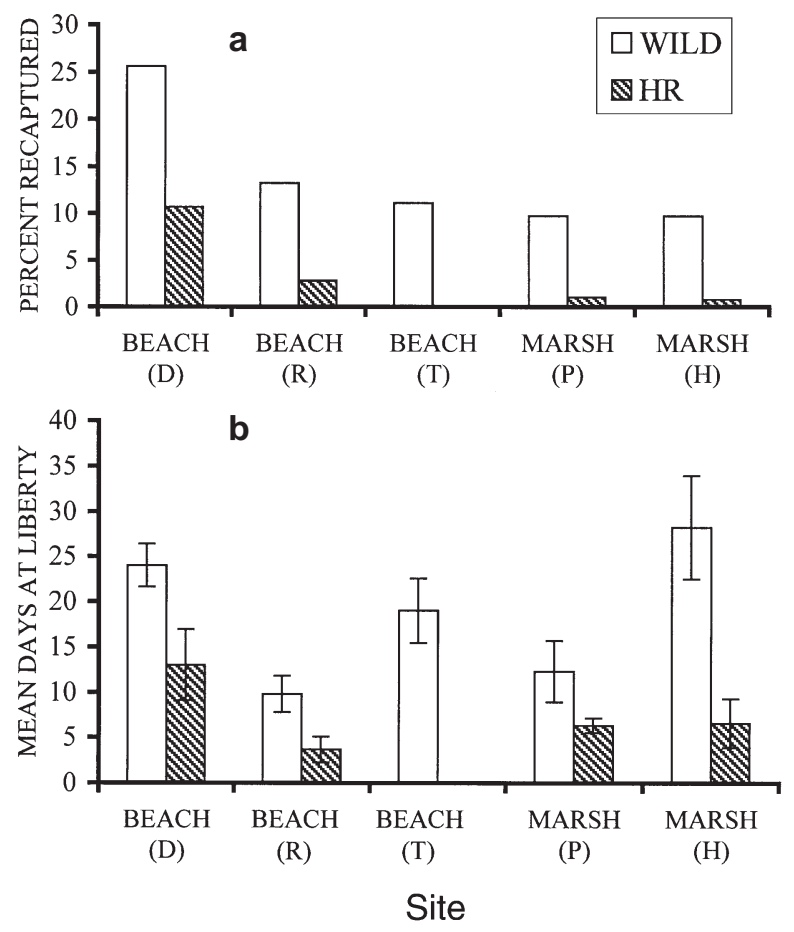

Fig. 4. Paralichthys dentatus. (a) Percent of total number (tagged or released) and (b) Mean days at liberty $( \pm \mathrm{SE})$ of wild (white bars) versus hatchery-reared (HR) (hatched bars) juvenile summer flounder recaptured in beach and marsh habitats from 2 June to 22 July. Both (a) and (b) are based on mark-recapture and experimental release trials. Pooled across sites, responses in both (a) and (b) were significantly less for HR than for wild fish (see text for significance levels)

recaptured HR fish that were individually tagged and re-released were subsequently recaptured. Because of the paucity of twice-or-more recaptured HR fish from which to gather estimates of field growth rates, we were unable to make comparisons of habitat- or site-specific growth rates, as estimated by releaserecapture and mark-recapture, between HR and wild fish. Qualitative comparisons of the percentage of recaptured fish and mean days at liberty of fish (based on data collected from June 3 to the end of the study) reveal that both (1) the percentage of individuals recaptured, and (2) mean days at liberty were considerably less for HR than for wild fish, regardless of habitat or site (Figs. 4a and b, respectively). Pooled across sites to increase statistical power, and using wild fish data collected after the release of HR fish, both the percentage of recaptured fish (log-linear $G$-test; $\chi^{2}{ }_{1}=$ 58.06; $\mathrm{p}<0.0001$ ), and mean days at liberty (Wilcoxon 2 -sample test, $Z=5.1348, \mathrm{p}<0.0001 ; \mathrm{n}=30$ for HR and 85 for wild fish) were significantly less for HR than for wild fish.

\section{Growth rates determined through caging}

There were no significant effects of fish status (HR versus HDHR versus wild; nested ANOVA: $F_{2,5.1}=0.02$, $\mathrm{p}=0.9836$ ) or habitat (beach versus marsh; nested ANOVA: $F_{1,2.1}=0.34 ; \mathrm{p}=0.6154$ ) on mean growth rates (Fig. 5; Appendix 2a). None of the treatment interaction terms were significant ( $p>0.05$ in all cases).

\section{Stomach content analyses}

The diets of caged HR, HDHR, and wild fish were similar, indicating that HR fish are capable of adapting to a natural prey base (i.e. a diet similar to wild conspecifics), regardless of flounder density. There was no significant effect of habitat, fish status, or caging trial on mean stomach content mass ( $p>0.05$ in all cases; Appendix 2b). The sites-within-habitats factor was nearly significant (nested ANOVA: $F_{2,4.6}=4.86 ; \mathrm{p}=$ $0.0737)$. None of the treatment interaction terms were significant ( $p>0.05$ in all cases).

Fish density within cages had little effect on the occurrence and importance of prey taxa. The diets of HDHR and HR fish were similar in composition and in

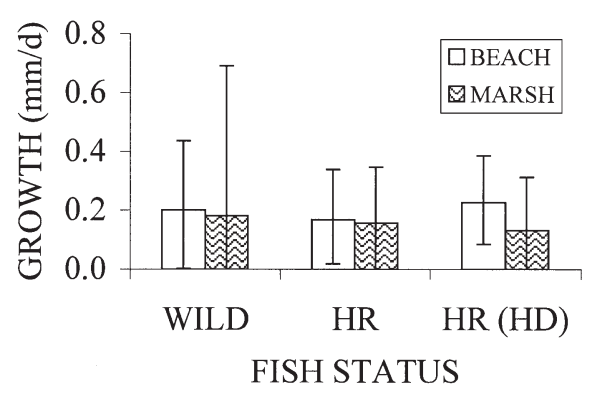

Fig. 5. Paralichthys dentatus. Back-transformed, least square mean growth rates ( \pm estimated $95 \%$ CI bounds) of wild $(\mathrm{n}=8)$, hatchery-reared $\left(\mathrm{HR}_{i} \mathrm{n}=13\right)$, and high-density $\mathrm{HR}$ (HDHR; $\mathrm{n}=14$ ) juvenile summer flounder in beach (white bars) and marsh (patterned bars) habitats, based on caging trials. There were no statistical differences between treatments (ANOVA, $\mathrm{p}>0.05$ in all cases) 

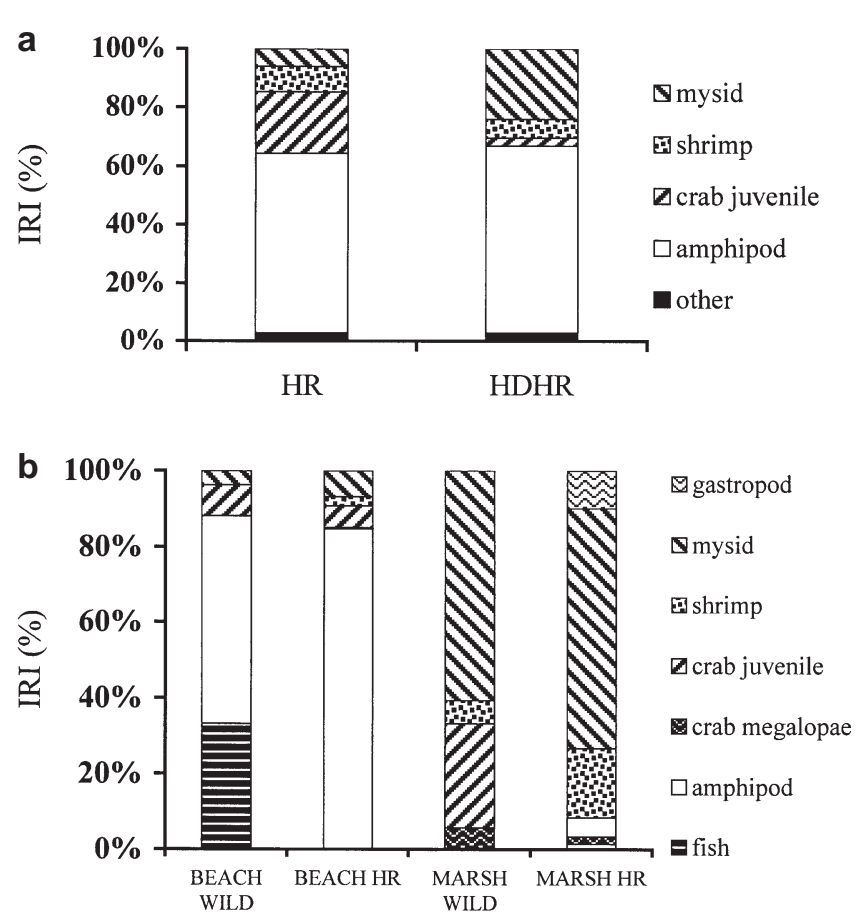

Fig. 6. Paralichthys dentatus. (a) Percent index of relative importance (\%IRI) of prey taxa for hatchery-reared (HR) $(\mathrm{n}=9)$ and high-density HR $\left(\mathrm{HDHR}_{i} \mathrm{n}=33\right)$ juvenile summer flounder from caging trials. (b) \%IRI values for HR and wild juvenile summer flounder from caging trials in beach and marsh habitats. HR data in (b) are the HR and HDHR data from (a) combined. Sample sizes are as follows: HR-beach $=$ 26 , wild-beach $=4, \mathrm{HR}$-marsh $=17$, wild-marsh $=4$

\%IRI values of dominant taxa (Fig. 6a). Amphipods had the greatest \%IRI value of all prey taxa for both HDHR and HR fish. Mysid shrimp and brachyuran crab juveniles were also characterized by relatively large \%IRI values, the order of which was dependent on treatment (HDHR versus HR). Palaemonid and Alpheid shrimp accounted for $\leq 10 \%$ IRI in each of the fish treatments.

Based on the similarity in diet composition of caged HDHR and HR fish, these 2 treatments were combined to simplify comparisons of diets of caged HR fish and caged wild fish across habitats. Qualitatively, the composition of diets between caged HR and caged wild fish was generally similar, regardless of habitat (Fig. 6b). In beach habitats, both HR and wild fish consumed amphipods, crab juveniles and mysids. In marsh habitats, both HR and wild fish consumed mysids, Palaemonid shrimp, crab juveniles and crab megalopae. Quantitatively, \%IRI values for HR and wild fish were similar for some prey items, but differed considerably for others. In beach habitats, amphipods had the highest \%IRI values for both HR (84\%) and wild $(49 \%)$ fish. Both brachyuran crab juveniles and mysid shrimp had small \%IRI values for HR $(5.7 \%$ and

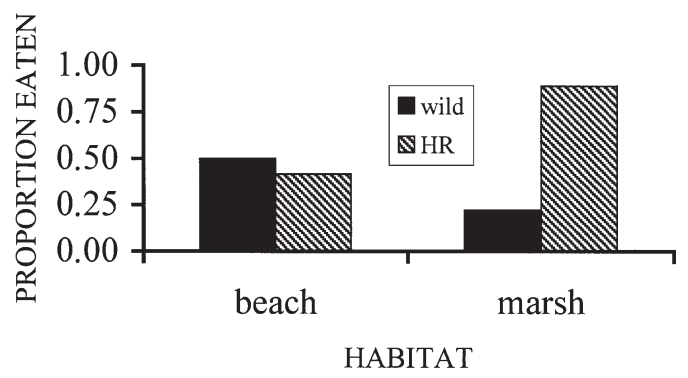

Fig. 7. Paralichthys dentatus. Predation-induced mortality of tethered hatchery-reared (HR) (hatched bars) and wild (dark bars) juvenile summer flounder in beach $(\mathrm{n}=24)$ and marsh ( $\mathrm{n}=18$ ) habitats. There was a significant fish status (HR versus wild) by habitat (beach versus marsh) interaction (loglinear $G$-test; $\mathrm{p}=0.0099$ )

$6.8 \%$, respectively) and wild ( $7.3 \%$ and $3.4 \%$, respectively) fish. The most conspicuous difference between HR and wild fish in beach habitats was that fish prey had a relatively large \%IRI value for wild fish $(30.02 \%)$, but a $\%$ IRI of $0 \%$ for HR fish (Fig. 6b). In marsh habitats, the dominant prey taxon for both HR and wild fish was mysid shrimp (\%IRI values of 60.6 and $62.38 \%$, respectively). Palaemonid shrimp and brachyuran crab juveniles were also characterized by relatively large $\%$ IRI values for both HR (18 and $5.1 \%$, respectively) and wild (6.1 and $27.5 \%$, respectively) fish. Gastropods occurred in the diets of HR fish (\%IRI $=9.85 \%)$, but not in the diets of wild fish (Fig. 6b).

\section{Predation-induced mortality rates}

There was a significant effect of fish status (HR versus wild) (log-linear $G$-test; $\chi^{2}=4.28 ; \mathrm{p}=0.0386$ ), but not habitat (beach versus marsh) (log-linear $G$-test; $\chi^{2}=0.57$; $\mathrm{p}=0.4485$ ), on the frequency of predation-induced mortality of tethered fish (Fig. 7). There was a significant fish status $\times$ habitat interaction (log-linear $G$-test; $\chi^{2}=6.66$; $\mathrm{p}=0.0099$ ), as predation on HR fish was greater than predation on wild fish in marsh habitats, but slightly less than predation on wild fish in beach habitats (Fig. 7). Predation-induced mortality was nearly $100 \%$ at Duke and Radio beaches, but $0 \%$ at Towne Beach (Table 3 ). Predation-induced mortality was relatively constant across sites in marsh habitats (Table 3 ).

\section{DISCUSSION}

\section{Implications for biological feasibility: performance of HR versus wild fish}

Since both the biological feasibility and economic potential of stock enhancement efforts rest on the 
Table 3. Paralichthys dentatus. Mortality of tethered fish, by site and habitat. Each entry in the 'Wild' and 'HR' (hatcheryreared) columns represents the number of fish suffering predation-induced mortality over the number of fish tethered.

Duplicate site entries indicate separate sample days

\begin{tabular}{|lccc|}
\hline Habitat & Site & Wild & HR \\
\hline Beach & Radio & $3 / 3$ & $3 / 3$ \\
& Duke & $3 / 3$ & $2 / 3$ \\
& Towne & $0 / 3$ & $0 / 3$ \\
& Towne & $0 / 3$ & $0 / 3$ \\
Marsh & Causeway & $1 / 3$ & $3 / 3$ \\
& Prytherch & $0 / 3$ & $3 / 3$ \\
& Haystacks & $1 / 3$ & $2 / 3$ \\
\hline
\end{tabular}

ability of HR organisms to survive in the wild, it is imperative to make comparisons between the performance of HR and wild fish to determine the relative ability of HR fish to survive in natural nursery habitats. In this study, the $1546 \mathrm{HR}$ fish released fared poorly in comparison to wild fish. Although we were unable to make direct growth-rate comparisons between HR and wild fish based on mark-recapture trials, we were able to compare (1) percentages of marked fish that were recaptured and (2) estimated residence times (based on measurements of days at liberty) between HR and wild fish. Relatively high percentage recaptured values for wild fish throughout the study indicate relatively high survival rates. For example, more than $27 \%$ of all wild fish that were marked on Duke Beach were recaptured on subsequent sample dates. Since less than $10 \%$ of the Duke Beach site was sampled on a given sample date, recapturing $27 \%$ of all fish tagged, especially with a mean DL on Duke Beach of $\sim 25 d$, suggests that survival of wild fish in the nursery habitats used in this study is remarkably high. Under the extremely conservative assumption that all unrecaptured wild fish perished (even though daily sampling covered less than $10 \%$ of the available habitat), we calculate a daily survival rate of $\sim 95 \%$ at this site. In every site in which HR fish were released in this study, the percentage of HR fish recaptured was considerably less than that of wild fish. At Duke Beach, the site in which the difference in percentage recaptured between HR and wild fish was least, the percentage of wild fish recaptured was more than 2.5 times that of HR fish. In other sites, the differential was more than twice that in Duke Beach ( 4.7 times greater on Radio Beach, 9.5 times greater in Prytherch Marsh, and 12 times greater in Haystacks Marsh). The differences in percentages recaptured between HR and wild fish that were evident in all sites, regardless of habitat, suggest that the HR fish in this study did not persist in these nursery habitats at rates comparable to those of wild fish. Comparisons of site- and habitatspecific days at liberty of HR versus wild fish provide further evidence of the lack of persistence of HR fish. Measurements of days at liberty of wild fish indicate that wild individuals utilize both beach and marsh habitats as nursery areas for relatively long periods of time (from the smallest mean of $\sim 10 \mathrm{~d}$ on Radio Beach, to the greatest value of $\sim 31 \mathrm{~d}$ in Haystacks Marsh). Days at liberty of HR fish were poor in comparison to those of wild fish in every site, again suggesting that HR fish were simply not persisting in the nursery areas that served as experimental sites in this study.

A lack of persistence of HR fish in nursery habitats could have been caused by 2 possible mechanisms: (1) emigration and (2) mortality of the released fish. We suggest that the lack of persistence of HR fish in nursery habitats was due to mortality of HR fish, and not to emigration from these nursery habitats. We support this suggestion with the following evidence. First, the behavior of HR fish was observed immediately after release by a snorkeler swimming behind the releasers. Nearly $100 \%$ of the observed released fish swam quickly to the benthos and remained still, with some of these fish burying. These behaviors are not consistent with mass emigration of released fish (although we have no field observations of nocturnal behavior). Second, in an attempt to identify whether emigration from release sites occurred, we irregularly sampled outside of sites, and never caught released fish. Third, based on the results of our mark-recapture work, wild fish remain in these nursery habitats for relatively long periods of time (60 to $90 \mathrm{~d}$ at liberty were often observed). If HR fish exhibit similar behaviors as wild fish in the wild (the HR fish are the progeny of wild-caught adults), then the HR fish would not have emigrated immediately from the release habitats. Fourth, both Prytherch and Haystacks marsh sites were 'blind' marshes, so that tidal in- and outflow occurred through small, bottleneck channels. Emigration from either of the marsh sites could only have occurred through these bottleneck channels; random dispersive movement in this case would nearly always have resulted in HR fish remaining in the release site. Beach sites were chosen so that there were physical barriers to lateral movement. Fifth, we witnessed rapid post-release mortality on Duke beach, in which several HR fish were preyed upon by juvenile (40 to $80 \mathrm{~mm}$ estimated carapace width) blue crabs Callinectes sapidus within minutes of their release. Sixth, the transition zones between the nursery habitats in which releases occurred and deeper waters were generally characterized by high densities of potential predators (particularly age 1+ flounders) (J. C. Taylor \& G. T. Kellison pers. obs.). 
These predators may have served to discourage HR fish from emigrating to deeper waters, as we suggest they do for juvenile wild fish. In any event, deeper waters in our study system were characterized by relatively high abundances of piscivores (compared with nursery flats) (J. C. Taylor \& G. T. Kellison pers. obs.), so HR fish emigrating to adjacent, deeper waters would have been unlikely to survive (i.e. emigration at or near the size-at-release may be tantamount to mortality). Seventh, HR individuals of the closely related Japanese flounder Paralichthys olivaceus suffer rapid (on a scale of days) and extensive post-release mortality, most likely due to predation (Yamashita et al. 1994, Furuta 1996, Furuta et al. 1997). These 7 pieces of evidence suggest that the rapid disappearance of HR fish from release sites was due to within-site mortality of released fish, and not to emigration.

\section{Identifying the problem}

If mechanisms underlying increased mortality of HR fish can be identified, then these mechanisms can plausibly be addressed by altering rearing techniques in an attempt to mitigate post-release mortality and maximize the potential of stock enhancement efforts. If the HR fish in this study did perish within the release sites (as suggested above), then it is prudent to attempt to identify the mechanism(s) underlying this increased mortality, as compared with that of wild fish. We will assume that the rapid disappearance of HR fish from release sites in this study was not a result of pathogeninduced mortality, since caged HR and wild fish showed no signs of differential mortality. Thus, mechanisms to increase survival of HR fish, as compared with wild fish, rest with the ability of HR fish to consume food resources and grow in the wild, and avoid predation.

Mechanism: inability to consume food resources and grow?

Hatchery-reared fish generally are raised in an environment that is void of natural stimuli and behavioral cues (Olla et al. 1998). Because HR fish (including those in this study) are typically bred with prepared diets, and rarely receive live foods due to logistic and financial constraints, released fish may be ill-equipped to adjust to natural, live diets subsequent to release. Nevertheless, our results indicate that, regardless of habitat, HR fish were capable of consuming amounts and taxa of prey (based on mass of stomach contents and stomach content analysis) and achieving growth rates (based on caging trials) over a $3 \mathrm{wk}$ period that were comparable to those of wild fish (validation of caging growth estimates is presented in Kellison et al. in press). These results are consistent with those of prior studies of HR fish, which suggest that HR fish may rapidly adapt to natural diets with experience (see, for example, Godin 1978, Ringler 1979, Webb \& Skadsen 1980, Paszkowski \& Olla 1985, Stradmeyer \& Thorpe 1987, Reiriz et al. 1998, Munakata et al. 2000).

\section{Density and growth}

Growth rates of caged HDHR fish in this study were not significantly different than those of caged HR and wild fish (in fact, they were nominally greater than those of wild fish in beach habitats). These results suggest that, even if HR fish remained or became closely aggregated following release (recall that fish were released a few at a time over a relatively broad spatial scale within release sites to minimize post-release clumping), they should have been able to achieve growth rates comparable to wild fish at natural densities $\left(\sim 0.01\right.$ to $\left.0.25 \mathrm{~m}^{-2}\right)$. Besides adding further evidence that an inability to feed and achieve 'natural' growth rates was not a mechanism underlying the poor post-release survival of HR fish in this study, these results are important in that post-release densities of HR fish in most stock enhancement situations will be well above natural densities. For stock enhancement efforts to be successful, post-release densities must be below the carrying capacity of the release environment (Munro \& Bell 1997). The results from this study indicate that food resources do not limit flounder growth at normal ('wild') densities, since caged HDHR fish achieved comparable growth rates to wild fish. Because wild fish generally do not occur at densities matching those of the HDHR treatment (density of caged HDHR fish was $\sim 3.8 \mathrm{~m}^{-2}$, while the highest observed density of wild fish in natural habitats in 1999 was $\sim 0.6 \mathrm{~m}^{-2}$ ), results suggest that wild fish at this life stage generally exist at densities below the resource carrying capacity of their nursery habitats, and that other mechanisms act to regulate population size within nurseries.

Mechanism: increased susceptibility to predation?

Hatchery-reared organisms of numerous species are more susceptible to predation than wild conspecifics (see, for example, Olla et al. 1994, Berejikian 1995, Furuta 1996, Furuta et al. 1998, Kellison et al. 2000). Previous work with HR summer flounder indicates that HR fish exhibit irregular behavioral patterns compared with wild conspecifics, spending significantly greater 
amounts of time swimming in the water column, and taking significantly longer periods of time to become cryptic (through burial or cryptic coloration) on the benthos (Kellison et al. 2000). Such anomalous behaviors, or 'behavioral deficits', were assumed to underlie the increased susceptibility to predation-induced mortality by blue crab Callinectes sapidus as predators in laboratory trials (Kellison et al. 2000) (aside from $C$. sapidus, the predator guild of juvenile summer flounder is, to our knowledge, undocumented). In this study, the rapid loss of HR fish from release habitats may have been a direct result of behavioral deficits, or an indirect result of an inability to quickly adapt to natural diets. For example, HR Japanese flounder have been shown to exhibit feeding behaviors (e.g. extended periods in the water column) that may make them more susceptible to predation than wild fish (Furuta 1996). Similar behaviors for the released fish in this study could underlie their hypothesized increased susceptibility to predation. Additionally, although HR fish exhibited similar diet composition and growth rates over the 3 wk caging period, it is improbable that HR fish immediately adapted to a wild diet upon their introduction into the wild. Depending on the length of time necessary for HR fish to adapt to a natural diet, released fish may have begun to experience hunger stimuli, and subsequently to search for food. This starvation behavior, if exhibited, may have caused HR fish to be increasingly susceptible to predation-induced mortality in 1 of 2 ways. First, starved fish may exhibit anomalous behavioral patterns in which they decrease predator vigilance behaviors and increase emphasis on finding food resources (Furuta et al. 1998). Second, HR fish in this study were conditioned to receiving pellet food from above (i.e. from surface waters; see Kellison et al. 2000 for discussion). If HR fish began to experience hunger, they may have exhibited upward swimming behaviors in search of food. Either of these mechanisms could have interacted with other behavioral abnormalities in HR fish (Kellison et al. 2000) to result in an increased susceptibility of HR fish to predationinduced mortality.

The tethering trials in this study resulted in considerably greater predation-induced mortality on HR than wild fish in marsh habitats (Prytherch, Haystacks, and Causeway sites). In beach habitats, predation-induced mortality was nearly equal between tethered HR and wild fish. Results of tethering trials in marsh habitat were generally consistent across sites, such that in every case either zero or 1 of 3 wild fish was eaten, while either 2 or 3 HR fish were eaten. In beach sites, however, results were much less consistent. Two beach sites were characterized by high predation-induced mortality (on Duke Beach, all but one HR fish was eaten, and on Radio Beach, all fish were eaten), while
1 site was characterized by no predation-induced mortality (no tethered fish were eaten on Towne Beach on either of the tethering sample dates). Although these observations represent small sample sizes and short times spans (i.e. only Towne Beach was replicated temporally), they raise the possibility that high intrahabitat variability may mask differences in flounder growth and survival between beach and marsh habitats, should they exist (see below).

\section{Habitat}

In the southeastern United States, summer flounder utilize both beach and marsh inter- and subtidal habitats as nursery areas. Thus, it was important to investigate habitat-specific performance of summer flounder, since (1) survival of released HR organisms (and thus success of stock enhancement efforts) may be extremely dependent on habitat quality (Stoner 1994, Leber \& Arce 1996), and (2) the output of such investigations may contribute significantly to information necessary to make informed habitat conservation decisions. Unfortunately, summer flounder occupy a rather wide geographical range, such that habitats utilized by summer flounder may differ considerably from those identified in this study (see, for example, Szedlmayer \& Able 1993, Able \& Kaiser 1994). This fact demonstrates a major potential impediment to the effective use of stock enhancement as a management tool: spatial and temporal variability in abiotic and biotic conditions may cause carefully determined optimal release scenarios for enhancement efforts to be applicable only at relatively small spatial and temporal scales. Nevertheless, habitat-specific performance studies, such as those described herein, are crucial to the success (local, regional, or otherwise) of planned enhancement efforts. If stock enhancement is to occur with summer flounder, then it will be critical to identify and release fish in habitats that optimize growth and survival, and contribute the largest number of recruits to the subsequent population stage.

To make inferences about optimal habitats for release, it was necessary to compare the performances of juvenile summer flounder between beach and marsh habitats. Although the abiotic variables we measured differed considerably between habitats, and although resident fauna may differ in beach versus marsh habitats (Peterson \& Peterson 1979, G. T. Kellison \& J. C. Taylor pers. obs., this study), our results did not support a hypothesis of differential performance (i.e. growth rates, residence times (based on mean days at liberty), and percent of wild or HR fish recaptured) of juvenile flounder between habitats. Instead, we found relatively high variability 
in response variables between sites within habitats, which suggests that release areas that optimize growth and survival may be more site-dependent than habitat-dependent (Pulliam 1988). Prior research suggests that there may be relatively large variability in habitat quality over very small spatial scales (due perhaps to patchy effects of temperature and dissolved oxygen stress, predation, and food availability), resulting in high intra-habitat variability in biological response variables (Halpin 1991, Stoner 1994, Underwood \& Chapman 1996). Therefore, caution should be exercised before making management or conservation decisions on habitat distinctions based on small sample sizes that may not have addressed possible variability between sites within a habitat.

\section{CONCLUSIONS}

\section{Is stock enhancement a recommendable management tool for summer flounder?}

Although post-release survival of HR flounder in this study was apparently poor, summer flounder stock enhancement is probably biologically feasible, as an addition of any individuals to the wild stock could be considered enhancement. Post-release survival might be increased by (1) improving methods of predatorconditioning, (2) releasing HR fish in sites that serve as natural refuges from predators, or (3) releasing fish of larger sizes. Nevertheless, conclusions regarding the responsible use of stock enhancement as a management tool can only be made if biological information (such as that presented in this study) is coupled with economic information (G. T. Kellison \& D. B. Eggleston unpubl.) to predict economic costs associated with stock enhancement relative to costs associated with alternative management approaches. If economic costs to achieve a management goal are minimized with a stock enhancement approach, then enhancement efforts may be the best method with which to manage or rebuild a fishery (assuming ecological concerns can be addressed).

Acknowledgements. Many thanks to Don Hoss and the NMFS/NOS Beaufort Laboratory for their provisions of encouragement, expertise, equipment, and laboratory space, all of which greatly facilitated the completion of this research. Dave Colby (NOS) provided the cages for growth trials, and Mark Fonseca (NOS) provided the current meter and valuable advice regarding our habitat measurements. Mark Wuenschel, Michael Martin, Brian Degan, Mikael Currimjoe, and Lisa Etherington provided valuable field and laboratory assistance. Thanks to the National Estuarine Research Reserve system for their cooperation in allowing us to utilize the Towne Beach site. John Miller, Jim Rice, and 4 anonymous reviewers made suggestions and put forth considerable effort to improve earlier versions of this manuscript, and Dennis Boos provided statistical advice. This project was partially funded by the University of North Carolina at Wilmington/North Carolina State University Cooperative PhD Program, and a grant from the National Science Foundation (OCE 97-34472) to D.B.E.

Appendix 1. Paralichthys dentatus. Mixed-model (sites within habitat = random factor), nested ANCOVA table for analysis of (a) growth rates and (b) days at liberty of mark-recaptured fish. Growth rate data were $\log _{\mathrm{e}}(x+1)$-transformed to satisfy the assumption of homogeneity of variances. The covariates 'tag day' and 'initial size' were included in analysis of growth rate and days at liberty, respectively, after satisfying the assumption of homogeneity of slopes. Error terms (denominators for $F$-ratio tests) were generated by the MIXED procedure in SAS. Growth rate and days at liberty data are displayed graphically (by site) in Fig. 2. MS: mean square

\begin{tabular}{|lrrrr|}
\hline Treatment & df & MS & Error term & p \\
\hline (a) Growth rates & & & & \\
Habitat & 1 & 0.570 & 0.5143 MS (Site [habitat]) +0.4857 MS (Residual) & 4.53 \\
Site(habitat) & 3 & 0.208 & Residual & 0.0981 \\
Tag day & 1 & 0.640 & Residual & 0.0016 \\
Residual & 109 & 0.038 & & 16.63 \\
& & & & $<0.0001$ \\
(b) Days at liberty & 1 & 1080.935 & 0.4183 MS (Site [habitat]) +0.5817 MS (Residual) & 2.12 \\
Habitat & 3 & 859.219 & Residual & 0.1958 \\
Site(habitat) & 1 & 3214.397 & Residual & 3.30 \\
Initial size & 109 & 260.549 & & 0.0232 \\
Residual & & & & 0.0006 \\
\end{tabular}


Appendix 2. Paralichthys dentatus. Mixed-model (sites within habitat = random factor), nested ANOVA table for analysis of (a) growth rate and (b) stomach content mass of caged fish. Growth and stomach content mass data were $\log _{\mathrm{e}}(\mathrm{growth}+1)-\mathrm{and}$ $\log _{e}$-transformed, respectively, to meet the assumption of homogeneity of variances. Error terms (denominators for F-ratio tests) were generated by the MIXED procedure in SAS. Growth rate data are displayed graphically in Fig. 5. MS: mean square

\begin{tabular}{|c|c|c|c|c|c|}
\hline Treatment & df & MS & Error term & $F$ & $\mathrm{p}$ \\
\hline \multicolumn{6}{|l|}{ (a) Growth rate } \\
\hline Fish status & 2 & 0.0002 & 0.912 MS $($ Status $\times$ Site $[$ habitat $)+0.088 \mathrm{MS}($ Residual $)$ & 0.02 & 0.9836 \\
\hline Habitat & 1 & 0.012 & $0.9659 \mathrm{MS}($ Site[habitat]) + 0.0341 MS (Residual) & 0.34 & 0.6154 \\
\hline Site(habitat) & 2 & 0.035 & $0.9506 \mathrm{MS}($ Status $\times$ Site[habitat]) $+0.0494 \mathrm{MS}$ (Residual) & 2.66 & 0.1708 \\
\hline Trial & 1 & 0.042 & Residual & 2.35 & 0.1396 \\
\hline Fish status $\times$ Habitat & 2 & 0.002 & 0.9547 MS (Status $\times$ Site[habitat]) + 0.0453 MS (Residual) & 0.13 & 0.8832 \\
\hline Fish status $\times$ Site(habitat) & 4 & 0.013 & Residual & 0.71 & 0.5920 \\
\hline Residual & 22 & 0.018 & & & \\
\hline \multicolumn{6}{|l|}{ (b) Stomach content mass } \\
\hline Fish status & 2 & 0.663 & 0.8928 MS (Status $\times$ site [habitat]) + 0.1072 MS (Residual) & 0.49 & 0.6381 \\
\hline Habitat & 1 & 20.202 & $0.9204 \mathrm{MS}($ Site[habitat]) + 0.0796 MS (Residual) & 3.32 & 0.2040 \\
\hline Site(habitat) & 2 & 6.450 & $0.9522 \mathrm{MS}($ Status $\times$ Site [habitat]) $+0.0478 \mathrm{MS}$ (Residual) & 4.86 & 0.0737 \\
\hline Trial & 1 & 0.055 & Residual & 0.03 & 0.8628 \\
\hline Fish status $\times$ Habitat & 2 & 2.854 & 0.8954 MS (Status $\times$ Site [habitat]) + 0.1046 MS (Residual) & 2.11 & 0.2111 \\
\hline Fish status $\times$ Site(habitat) & 4 & 1.302 & Residual & 0.72 & 0.5888 \\
\hline Residual & 21 & 1.812 & & & \\
\hline
\end{tabular}

\section{LITERATURE CITED}

Able KW, Kaiser SC (1994) Synthesis of summer flounder habitat parameters. NOAA Coastal Ocean Program, Decision Analysis Series No. 1. NOAA Coastal Ocean Office, Silver Spring, Maryland

Agnalt AL, van der Meeren GI, Jorstad KE, Naess h, Farestveit E, Nostvold E, Tvasand T, Korsoen E, Ydstebo L (1999) Stock enhancement of European lobster (Homarus gammarus): a large-scale experiment off South-western Norway. In: Howell BR, Moksness E, Tvasand T (eds) Stock enhancement and sea ranching. Blackwell Science, Oxford, p 401-420

Bartley DM (1999) Marine ranching: a global perspective. In: Howell BR, Moksness E, Tvasand T (eds) Stock enhancement and sea ranching. Blackwell Science, Oxford, p 79-90

Berejikian BA (1995) The effects of hatchery and wild ancestry and experience on the relative ability of steelhead trout fry (Oncorhynchus mykiss) to avoid a benthic predator. Can J Fish Aquat Sci 52(11):2476-2482

Borthern J, Agnalt AL, van der Meeren GI (1999) A bioeconomic evaluation of a stock enhancement project of European lobster: the simulation model LOBST.ECO with some preliminary results. In: Howell BR, Moksness E, Tvasand $\mathrm{T}$ (eds) Stock Enhancement and sea ranching. Blackwell Science, Oxford, p 583-596

Burke JS (1995) Role of feeding and prey distribution on summer and southern flounder in selection of estuarine nursery habitats. J Fish Biol 47(3):355-366

Burke JS, Miller JM, Hoss DE (1991) Immigration and settlement pattern of Paralichthys dentatus and P. lethostigma in an estuarine nursery ground, North Carolina, USA. Neth J Sea Res 27(3-4):393-405

Burke JS, Seikai T, Tanaka Y, Tanaka M (1999) Experimental intensive culture of summer flounder, Paralichthys dentatus. Aquaculture 176:135-144
Burke JS, Monaghan JP Jr, Yokoyama S (2000) Efforts to understand stock structure of summer flounder (Paralichthys dentatus) in North Carolina, USA. J Sea Res 44(1-2):111-122

Cortes E (1997) A critical review of methods of studying fish feeding based on analysis of stomach contents: application to elasmobranch fishes. Can J Fish Aquat Sci 54:726-738

Cowx IG (1999) An appraisal of stocking strategies in the light of developing country constraints. Fish Manage Ecol 6(1): 21-34

Edgar GJ, Shaw C (1995) The production and trophic ecology of shallow-water fish assemblages in southern Australia. 2. Diets of fishes and trophic relationships between fishes and benthos at Western Port, Victoria. J Exp Mar Biol Ecol 194(1):83-106

FAO (Food and Agriculture Organization of the United Nations) (2002) Summary: the state of world fisheries and aquaculture (SOFIA) - 1996. FAO, Rome, available at http://www.fao.org/sof/sofia/index_en.htm

Furuta S (1996) Predation on juvenile Japanese flounder (Paralichthys olivaceus) by diurnal piscivorous fish: field observations and laboratory experiments. In: Watanabe $Y$, Yamoshito Y, Oozeki Y (eds) Survival strategies in early life stages of marine resources. AA Balkema Publishers, Brookfield, VT, p 285-296

Furuta $\mathrm{S}$, Watanabe $\mathrm{T}$, Yamada $\mathrm{H}$, Nishida $\mathrm{T}$, Miyanaga $\mathrm{T}$ (1997) Changes in distribution, growth and abundance of hatchery-reared Japanese flounder Paralichthys olivaceus released in the coastal area of Tottori Prefecture. Nippon Suisan Gakkaishi 63(6):877-885

Furuta S, Watanabe T, Yamada H (1998) Predation by fishes on hatchery-reared Japanese flounder Paralichthys olivaceus juveniles released in the coastal area of Tottori Prefecture. Nippon Suisan Gakkaishi 64(1):1-7

Godin JGJ (1978) Behavior of juvenile pink salmon (Oncorhynchus gorbuscha Walbaum) toward novel prey: influ- 
ence of ontogeny and experience. Environ Biol Fish 3: 261-266

Halpin SPM (1991) Inter- and intra-marsh variation of habitat usage in intertidal fish with emphasis on the mummichog, Fundulus heteroclitus. Am Zool 31(5):136A

Hilborn R (1998) The economic performance of marine stock enhancement projects. Bull Mar Sci 62(2):661-674

Hoss DE, Thayer GW (1993) The importance of habitat to the early life history of estuarine dependent fishes. In: Fuiman LA (ed) Water quality and the early life stages of fishes. Am Fish Soc Symp 14:147-158

Howell BR, Moksness E, Tvasand T (1999) Stock enhancement and sea ranching. Blackwell Science, Oxford

Hurlbert SH (1984) Pseudoreplication and the design of ecological field experiments. Ecol Monogr 54(2):187-211

Kellison GT (2000) Evaluation of stock enhancement potential for summer flounder (Paralichthys dentatus): an integrated laboratory, field and modeling study. PhD thesis, North Carolina State University, Raleigh, NC

Kellison GT, Eggleston DB, Burke JS (2000) Comparative behaviour and survival of hatchery-reared versus wild summer flounder (Paralichthys dentatus). Can J Fish Aquat Sci 57(9):1870-1877

Kellison GT, Eggleston DB, Taylor JC, Burke JS (in press) An assessment of biases associated with caging, tethering, habitat-specific sampling of demersal fish. Estuaries

Kitada S, Taga Y, Kishino H (1992) Effectiveness of a stock enhancement program evaluated by a two-stage sampling survey of commercial landings. Can J Fish Aquat Sci 49(8): 1573-1582

Leber KM, Arce SM (1996) Stock enhancement in a commercial mullet, Mugil cephalus L., fishery in Hawaii. Fish Manage Ecol 3:261-278

Leber KM, Brennan MP, Arce SM (1998) Recruitment patterns of cultured juvenile Pacific threadfin, Polydactylus sexfilis (Polynemidae), released along sandy marine shores in Hawaii. Bull Mar Sci 62(2):389-408

Lenanton RC, Ayvazian SG, Dibden C, Jenkins G, Sarre G (1999) The use of stock enhancement to improve the catch rates of black bream, Anthopagrus butcheri (Munro) for Western Australian recreational fishers. In: Howell BR, Moksness E, Tvasand T (eds) Stock enhancement and sea ranching. Blackwell Science, Oxford, p 219-230

Masuda R, Tsukamoto K (1998) Stock enhancement in Japan: review and perspective. Bull Mar Sci 62(2):337-358

McEachron LW, McCarty CE, Vega RR (1994) Texas red drum enhancement works. Marine fish culture and enhancement, Conference Proceedings. Washington Sea Grant Program, Seattle, p 29-30

McMichael GA, Pearsons TN, Leider SA (1999) Behavioral interactions among hatchery-reared steelhead smolts and wild Oncorhynchus mykiss in natural streams. North Am J Fish Manage 19(4):948-956

Munakata A, Bjornsson BT, Jonsson E, Amano M, Ikuta K, Kitamura S, Kurokawa T, Aida K (2000) Post-release adaptation process of hatchery-reared honmasu salmon parr. J Fish Biol 56:163-172

Munro JL, Bell JD (1997) Enhancement of marine fisheries resources. Rev Fish Sci 5(2):185-222

Murphey PL, Fonseca MS (1995) Role of high and low energy seagrass beds as nursery areas for Penaeus duorarum in North Carolina. Mar Ecol Prog Ser 121(1-3):91-98

Olla BL, Davis MW, Ryer CH (1994) Behavioural deficits in hatchery-reared fish: potential effects on survival following release. Aquac Fish Manage 25(Suppl 1):19-34

Olla BL, Davis MW, Ryer CH (1998) Understanding how the hatchery environment represses or promotes the de- velopment of behavioural survival skills. Bull Mar Sci 62: 531-550

Otterå H, Kristiansen TS, Svåsand T, Nordeide JT, Nævdal G, Borge A, Pedersen JP (1999) Enhancement studies of Atlantic cod (Gadus morhua L.) in an exposed coastal area in western Norway. In: Howell BR, Moksness E, Svåsand T (eds) Stock enhancement and sea ranching. Blackwell Science, Oxford, p 257-276

Paszkowski CA, Olla BL (1985) Foraging behavior of hatchery-produced coho salmon (Oncorhynchus kisutch) smolts on live prey. Can J Fish Aquat Sci 42:1915-1921

Peterson CH, Black R (1994) An experimentalist's challenge: when artifacts of intervention interact with treatments. Mar Ecol Prog Ser 111(3):289-297

Peterson CH, Peterson NM (1979) The ecology of intertidal flats of North Carolina: a community profile. FWS/OBS 79/39, National Coastal Ecosystems Team, US Fish and Wildlife Service, Washington, DC

Pihl L, van der Veer HW (1992) Importance of exposure and habitat structure for the population density of 0 -group plaice, Pleuronectes platessa L., in coastal nursery areas. Proc First Int Symp Flatfish Ecology (Part 2). Neth J Sea Res 29:145-152

Pinkas L, Oliphant MS, Iverson ILK (1971) Food habits of albacore, bluefin tuna, and bonito in California waters. Fish Bull Calif Dep Fish Game 152:1-105

Powell AB, Schwartz FJ (1977) Distribution of paralichthid flounders (Bothidae: Paralichthys) in North Carolina estuaries. Chesapeake Sci 18(4):334-339

Pulliam HR (1988) Sources, sinks, and population regulation. Am Nat 132:652-661

Reiriz L, Nicieza AG, Brana F (1998) Prey selection by experienced and naïve juvenile Atlantic salmon. J Fish Biol 53(1):100-114

Rickards WL (1998) Sustainable flounder culture and fisheries: a regional approach involving Rhode Island, New Hampshire, Virginia, North Carolina, and South Carolina. In: Howell WH, Keller BJ, Park PK, McVey JP, Takayanagi K, Uekita Y (eds) Nutrition and technical development of aquaculture. Proc 26th US-Japan Aquaculture Symp, Durham, NH, Sep 16-18, 1997. University of New Hampshire Sea Grant Program, Durham, NH, p 17-20

Ringler NH (1979) Prey selection by drift-feeding brown trout (Salmo trutta). J Fish Res Board Can 36:392-403

Rosenberg AA, Fogarty MJ, Sissenwine MP, Beddington JR, Shepard JG (1993) Achieving sustainable use of renewable resources. Science 262:828-829

Satterthwaite FE (1946) An approximate distribution of estimates of variance components. Biometrics Bull 2:110-114

Stoner AW (1994) Significance of habitat and stock pretesting for enhancement of natural fisheries: experimental analyses with queen conch Strombas gigas. J World Aquacult Soc 25(1):155-165

Stradmeyer L, Thorpe JE (1987) The responses of hatcheryreared Atlantic salmon, Salmo salar L., parr to pelleted and wild prey. Aquac Fish Manage 18:51-61

Szedlmayer ST, Able KW (1993) Ultrasonic telemetry of age-0 summer flounder, Paralichthys dentatus, movements in a southern New Jersey estuary. Copeia 3:728-736

Travis J, Coleman FC, Grimes CB, Conover D, Bert TM, Tringali M (1998) Critically assessing stock enhancement: an introduction to the Mote Symposium. Bull Mar Sci 62(2):305-311

Underwood AJ, Chapman MG (1996) Scales of spatial patterns of distribution of intertidal invertebrates. Oecologia 107(2):212-224

Waters EB (1996) Sustainable flounder culture and fisheries. 
North Carolina Sea Grant Publication, UNC-SG-96-14. North Carolina State University, Raleigh, NC

Waters EB, Mosher K (1999) Flounder aquaculture and stock enhancement in North Carolina: issues, opportunities and recommendations. North Carolina Sea Grant Publication, UNC-SG-99-02. North Carolina State University, Raleigh, $\mathrm{NC}$

Webb PW, Skadsen JM (1980) Strike tactics of Esox. Can J Zool 58:1462-1469

Editorial responsibility: Otto Kinne (Editor),

Oldendorf/Luhe, Germany
Yamashita Y, Yamada H (1999) Release strategy for Japanese flounder fry in stock enhancement programmes. In: Howell BR, Moksness E, Tvasand T (eds) Stock enhancement and sea ranching. Blackwell Science, Oxford, p 191-204

Yamashita Y, Nagahora S, Yamada H, Kitigawa D (1994) Effects of release size on survival and growth of Japanese flounder Paralichthys olivaceus in coastal waters off Iwate Prefecture, northeastern Japan. Mar Ecol Prog Ser 105(3): 269-276

Submitted: June 25, 2001; Accepted: November 19, 2002

Proofs received from author(s): March 3, 2003 